\title{
The Effects of Titanium Dioxide Nanoparticles on the Growth and Development of Sorghum Bicolor (L.) Moenech
}

Adam Gregory Shoemaker

Missouri State University, Shoemaker23@live.missouristate.edu

As with any intellectual project, the content and views expressed in this thesis may be considered objectionable by some readers. However, this student-scholar's work has been judged to have academic value by the student's thesis committee members trained in the discipline. The content and views expressed in this thesis are those of the student-scholar and are not endorsed by Missouri State University, its Graduate College, or its employees.

\section{Follow this and additional works at: https://bearworks.missouristate.edu/theses}

Part of the Agronomy and Crop Sciences Commons, Biology Commons, and the Plant Biology Commons

\section{Recommended Citation}

Shoemaker, Adam Gregory, "The Effects of Titanium Dioxide Nanoparticles on the Growth and Development of Sorghum Bicolor (L.) Moenech" (2020). MSU Graduate Theses. 3480.

https://bearworks.missouristate.edu/theses/3480

This article or document was made available through BearWorks, the institutional repository of Missouri State University. The work contained in it may be protected by copyright and require permission of the copyright holder for reuse or redistribution.

For more information, please contact BearWorks@library.missouristate.edu. 


\title{
THE EFFECTS OF TITANIUM DIOXIDE NANOPARTICLES ON THE GROWTH AND DEVELOPMENT OF SORGHUM BICOLOR (L.) MOENECH
}

\author{
A Master's Thesis \\ Presented to \\ The Graduate College of \\ Missouri State University
}

\author{
In Partial Fulfillment \\ Of the Requirements for the Degree \\ Master of Science, Biology
}

By

Adam Gregory Shoemaker

May 2020 
Copyright 2019 by Adam Gregory Shoemaker 
THE EFFECTS OF TITANIUM DIOXIDE NANOPARTICLES ON THE GROWTH AND DEVELOPMENT OF SORGHUM BICOLOR (L.) MOENECH

Biology

Missouri State University, May 2020

Master of Science

Adam Gregory Shoemaker

\begin{abstract}
Engineered nanoparticles (ENPs) have seen a drastic increase in their use over the past decade in various consumer products. ENPs will therefore enter terrestrial ecosystems and soils with increasing frequencies, yet research into the effects of ENPs on living organisms and crops is greatly lacking. Currently, there is only one major study reported on the effects of a single ENP, silver quantum dots, on Sorghum bicolor, the $5^{\text {th }}$ largest crop in the world. I examined the effects of a commonly used metal oxide nanoparticle, titanium dioxide $\left(\mathrm{TiO}_{2}\right)$, on the growth and development of sorghum grown in petri dishes $(\mathrm{n}=25)$ with agar media and Murashige and Skoog (MS) media with concentrations of 5, 10, 20, and $40 \mu \mathrm{g} / \mathrm{ml}$. I measured seedling germination rates, gas exchange rates using a LI-6400 Portable Photosynthesis System, and biomass after 14 days of growth in a growth chamber. There is a significant decrease of on instantaneous water use efficiency rates due to increasing $\mathrm{TiO}_{2}$ concentrations, but all other gas exchange rates, germination rates, and biomass accumulation were not significant. I also grew sorghum in a greenhouse in potting soil $(\mathrm{n}=36$ pots) with concentrations of $100,200,500$, and $1000 \mathrm{mg} / \mathrm{kg}$. I measured sorghum physiology and biomass accumulation at full maturity. There were no measurable effects on physiology or biomass accumulation. While my research indicates no negative effects of this ENP on the growth or development in sorghum, further research will be necessary to identify if $\mathrm{TiO}_{2}$ ENPs are taken up and translocated by the plant, as well as possible intergenerational effects of ENP exposure. Future research may also be conducted into the possible application of $\mathrm{TiO}_{2}$ as an antimicrobial agent for use in pesticides or herbicides if no negative effects are found.
\end{abstract}

KEYWORDS: Sorghum bicolor, nanomaterials, nanoparticles, titanium dioxide, physiology 


\title{
THE EFFECTS OF TITANIUM DIOXIDE NANOPARTICLES ON THE GROWTH AND DEVELOPMENT OF SORGHUM BICOLOR (L.) MOENECH
}

\author{
By \\ Adam Gregory Shoemaker \\ A Master's Thesis \\ Submitted to the Graduate College \\ Of Missouri State University \\ In Partial Fulfillment of the Requirements \\ For the Degree of Master's of Science, Biology
}

May 2020

Approved:

Alexander Wait, Ph.D., Thesis Committee Chair

Lazslo Kovacs, Ph.D., Committee Member

Cyren Rico, Ph.D., Committee Member

Julie Masterson, Ph.D., Dean of the Graduate College

In the interest of academic freedom and the principle of free speech, approval of this thesis indicates the format is acceptable and meets the academic criteria for the discipline as determined by the faculty that constitute the thesis committee. The content and views expressed in this thesis are those of the student-scholar and are not endorsed by Missouri State University, its Graduate College, or its employees. 


\section{ACKNOWLEDGEMENTS}

I would like to thank the following people for their support during the course of my graduate studies.

I would like to thank Dr. Wait for his support and advice in improving the quality of my project and his help with completing my thesis. I am grateful for his advice on how to properly design an experiment, and his guidance in how to properly collect and analyze data.

I would also like to thank Dr. Kovacs and Dr. Rico for being part of my committee, and for always being open to answer questions I may have had.

I am thankful for Dr. Kovacs and his lab, who shared their protocol for properly sterilizing and plating a suspension of nanoparticle containing agar medium.

I would also like to thank the Jordan Valley Innovation Center in Springfield for providing the proper safety training for working with nanomaterials.

Finally, I would like to express my gratitude to my entire family for supporting me through this project and encouraging me to do my best at all times. 


\section{TABLE OF CONTENTS}

Introduction

Page 1

1.1. Background

Page 1

1.2. Effects on ENMs on Plant Growth and Development

Page 2

1.3. Effects of TiO2 ENPs on Plant Growth and

Development

Page 4

1.4. Background to Sorghum Bicolor (L.) Moenech Page 6

$\begin{array}{ll}\text { 1.5. Physiology of Sorghum } & \text { Page } 7\end{array}$

$\begin{array}{ll}\text { 1.6. Research Goals and Questions } & \text { Page } 8\end{array}$

Methods

Page 9

2.1. Overview

Page 9

2.2 In vitro Experiments; Germination, Growth, and Physiology

Page 9

2.3. Soil Experiment: Growths $\quad$ Page 11

2.4. Statistical Analysis $\quad$ Page 12

Results

Page 14

3.1. Effect of TiO2 Nanoparticle Treatments on Seedling Germination, Biomass, and Root Physiology of Sorghum bicolor grown in Agar Media

Page 14

3.2. Effect of $\mathrm{TiO} 2$ Nanoparticle Treatments on Gas

Exchange in Sorghum bicolor grown in Agar Media

Page 15

3.3. Effects of $\mathrm{TiO} 2$ Nanoparticle Treatments on Growth, Damage, and Biomass of Sorghum bicolor grown in Soil

Page 16

Discussion

Page 18

References

Page 20

Appendix: ANOVA tables

Page 27 


\section{LIST OF TABLES}

Table 1. Seedling germination rate, plant dry weight biomass, root length, and root area of sorghum grown for 14 days in agar media

Page 24

Table 2. Photosynthetic rate, conductance rate, transpiration rate, and water use efficiency of sorghum grown for 14 days in agar media.

Page 24

Table 3. Growth response of sorghum grown in soil.

Page 25 


\section{LIST OF FIGURES}

Figure 1. Mean dry weight of full plant, shoots, and roots of Sorghum bicolor $(n=25)$ in controls and different concentrations of $\mathrm{TiO} 2$ nanoparticle treatments after 14 days of growth in agar media.

Page 26

Figure 2. Mean dry weight of shoots, roots, and tassel head of Sorghum bicolor $(n=36)$ in controls and different concentrations of $\mathrm{TiO} 2$ nanoparticle Page 26 treatments after growing to full maturity in soil. 


\section{INTRODUCTION}

\subsection{Background}

Engineered nanomaterials and nanoparticles (ENMs and ENPs, respectively herein) have become a common material in many products with billions of dollars invested in their development and use worldwide (Blind et al. 2008; García et al. 2011; Gottschalk et al. 2013). ENMs are small particles that range from 1 to $100 \mathrm{~nm}$. Naturally occurring nanoparticles are common in the environment, originating mainly from volcanic ash, burning fossil fuels and trash, the breakdown of plastics and dust storms (Auffan et al. 2009; Klaine et al. 2009; Ma et al. 2010; Gottschalk et al. 2013). On the other hand, ENMs have only recently been produced for a wide range of uses, including many pharmaceutical, biomedical, cosmetic, computer chip, and environmental applications and products (Nowack \& Bucheli, 2007; Keller et al. 2010; Aslani et al. 2014). $\mathrm{ZnO}$ and $\mathrm{TiO}_{2}$ ENMs are widely used in cosmetics, sunscreens, and bottle coatings due to being visibly transparent while having an ultraviolet blocking ability (García et al. 2011; Aslani et al. 2014; Teszlák et al. 2018). $\mathrm{CeO}_{2}$ is widely used as a combustion catalyst in diesel fuels, and in oxygen pumps, gas sensors and solar cells (Aslani et al. 2014). $\mathrm{Fe}_{3} \mathrm{O}_{4}$ is important in many applications of nano-therapy, in the removal of contaminants, in data processing and storage applications, and in pigments for paint dyes (García et al. 2011). It is estimated that in 2004, there were several thousands of tons of ENMs that were released into the environment through sewage sludge, landfills, and biosolid applications for fertilization, and the amounts released are expected to increase to almost half a million tons by 2020 (Mauer-Jones et al. 2013). In 2014 , it was estimated that more than $15 \%$ of all products created worldwide rely on some type of nanotechnology in the creation process, by 2015 the nanotechnology market may reach 
\$1 trillion, and over 58,000 tons of metal oxide ENMs are estimated to be produced yearly between 2011 and 2020 (Nel et al. 2006; Aslani et al. 2014).

While research into the development and use of ENMs in various sectors has increased greatly, research on the biological impacts of ENMs is lacking (Sharifi et al. 2016). EMN's can enter the environment through both intentional and unintentional releases, including waste streams from manufacturers and atmospheric emissions, biosolids from waste treatment facilities, pesticide applications to crops, and accidental spillage of consumer products (García et al. 2011). This allows the ENMs to encounter organisms through multiple routes (Aslani et al. 2014). The mechanisms behind the uptake of various ENMs by organisms is not completely understood, and risk assessments and toxicological studies of ENMs on living organisms is essential to understand the potential negative effects (Hegde et al. 2016).

Due to the small size of ENMs, they generally have unique properties that vary from similar bulk materials with a larger size, caused by a high surface-to-volume ratio and different optical properties, which can change their chemical, mechanical, optical, electric, and magnetic properties (Buzea et al. 2007; Auffin et al. 2009; Aslani et al. 2014; Sharifi et al. 2016). While these differences may make ENMs useful for various industrial processes, they can also make them toxic, which can cause harm to the environment and agricultural systems (Cornelis et al. 2010; Aslani et al. 2014).

\subsection{Effects on ENMs on Plant Growth and Development}

So far, most studies on the biological and ecological effects of ENMs focus on aquatic organisms, and there is a need for understanding how they can affect the growth and development of plants, especially in major crop species (Lee et al. 2012; Maurer-Jones et al. 
2013; Aslani et al. 2014; Siddiqui et al. 2015). Hegde et al. (2016) states that several studies reported higher ENM concentrations in soil than in water or air. Due to most nanoparticles being reactive in the environment, there is a high potential for them to be taken up by various crop plants and transferred through the roots to the shoot and leaves, especially during the juvenile stage of development (Ma et al. 2010; Siddiqui et al. 2015). Depending on the size of the ENM, it is possible for them to be taken up through the roots of the plant and translocated through various tissues, as demonstrated with iron oxide ENP uptake by pumpkins (Ma et al. 2010). Similar ENPs, however, cannot be taken up by different plants, exemplified by the inability of lima beans to take up iron oxide ENPs (Ma et al. 2010).

The properties of ENMs can change depending on the media by dissolution, agglomeration, sedimentation, or a change in surface moieties, which can impact the degree of potential positive or negative ecological impacts, although most nanoparticles interact with environmental systems as an aggregate (Keller et al. 2010; García et al. 2011; Maurer-Jones et al. 2013). The rate of aggregation in ENMs can be affected by several factors, including an increasing ionic strength, the size and surface area of a nanoparticle, and the presence of various macromolecules in the media (Maurer-Jones et al. 2013). The size of a nanoparticle is important in determining the various transformations it can undergo, and can similarly impact its reactivity, transport, and toxicity in the environment (Keller et al. 2010). From what is currently known, metal oxide ENPs can produce stress on plants by affecting chlorophyll and chloroplasts or through generating excess reactive oxygen species (ROS), which can be induced by both active and inert ENMs and will indicate oxidative stress, damage to cell proteins, lipids, and carbohydrates, and gene expression in plants (Siddiqui et al. 2015; Sharifi et al. 2016). It is hypothesized that plant growth inhibition due to ENPs may not be solely due to chemical 
phytotoxicity, but may also be due to the physical interactions of the ENPs with plants, such as ENPs blocking apoplastic trafficking in intercellular spaces of the cell wall (Ma et al. 2010). For example, in a study with Zea mays, seedlings exposed to $\mathrm{TiO}_{2}$ ENPs and bentonite had inhibition of leaf growth and transpiration due to a reduction in hydraulic conductivity, as well as a $3.3 \mathrm{~nm}$ decrease in the cell wall pores (Asli \& Neumann, 2009).

The application of ENMs in agriculture has also been proposed to improve the yield of various plants for food, fuel, and animal feed; however, that research still leaves large gaps in knowledge about the effects of ENMs on most plants (Aslani et al. 2014; Pandey et al. 2018). The response of plants to various ENMs can range from increasing yield and growth rate to being toxic and inducing cell death. Carbon nanotubes (CNTs) are an extensively studied nanoparticle, and a variety of responses have been observed ranging from boosting the germination rate of tomato seedlings and increasing the water uptake, to inhibiting the mutigenerational reproductive capacity and biomass of wheat (Aslani et al. 2014; Rico et al. 2016). CNT exposure also increased germination rates and shoot length of sorghum seedlings, and increased biomass production, which is useful for crops like sorghum used in biofuel production (Pandey et al. 2018). Nanotechnology is also being used in agriculture to increase the efficiency of pesticides and to stop fertilizer from leaching into the ground and water, and to increase the growth and development of some plants due to the ability of some ENMs to increase plant growth (Siddiqui et al. 2015).

\subsection{Effects of $\mathrm{TiO}_{2}$ ENPs on Plant Growth and Development}

Information on the impact of $\mathrm{TiO}_{2}$ ENPs on plants is currently lacking, but current studies indicate they may generate ROS when interacting with living organisms or ultraviolet 
radiation (Li et al. 2015). $\mathrm{TiO}_{2}$ ENMs may also have antimicrobial properties, one of which could be an impact on the soil microbiome (Vance et al. 2015; Hegde et al. 2016). It is thought that $\mathrm{TiO}_{2}$ ENPs can act as a photocatalyst and induce redox reactions, as well as promoting seed vigor, chlorophyll formation, and the stimulation of Rubisco, which increases photosynthesis and plant growth (Siddiqui et al. 2015; Hegde et al. 2016). Several other studies report that $\mathrm{TiO}_{2}$ ENPs may stimulate plant growth at lower doses but can prove toxic at higher concentrations (Klaine et al. 2009).

Various studies report that $\mathrm{TiO}_{2}$ ENPs may have positive impacts on the growth and development of various plants. Kurepa et al., (2010) reported that in soybeans, seeds treated with $\mathrm{TiO}_{2}$ showed an increase of $73 \%$ in dry weight, a 3 times higher photosynthetic rate, and a $45 \%$ increase in chlorophyll a formation. In spinach seeds, they found that the increase in germination correlated with a reduction in the sizes of the ENP. It was also reported that in the anatase phase, $\mathrm{TiO}_{2}$ increased plant growth through improving nitrogen metabolism, which promotes the adsorption of nitrate, while also indicating a negative effect towards seed germination percentage and the number of roots in Oryza sativa L (Aslani et al. 2014). Mahmoodzadeh et al., (2013) reported an increase in germination and growth of canola treated with $\mathrm{TiO}_{2}$. Other studies show that $\mathrm{TiO}_{2}$ ENPs may have negative effects on plant growth, such as Jaberzadeh et al., (2013), who reported that $\mathrm{TiO}_{2}$ treatments affected wheat plant growth to be similar to plants under water stressed conditions. A study by Asli \& Neumann (2009) reported that $\mathrm{TiO}_{2}$ ENPs applied to Zea mays grown in bentonite soil did have a negative impact on primary root development, and subsequently plant growth, although long term effects on the mature plant were not significant. Finally, other studies indicate that $\mathrm{TiO}_{2}$ ENPs may not have any affect at all on plant growth. For example, Seeger et al. (2009) reported that there was no significant changes in any 
measured growth parameters of willow trees applied with $\mathrm{TiO}_{2}$ ENPs, perhaps due to particles being rapidly lost from the application solution due to sedimentation and aggregation, as well as possible adsorption to the roots. Tang et al. (2013) found that $\mathrm{TiO}_{2} \mathrm{ENPs}$ alone did not cause any significant inhibitory effects except when Zinc ENMs were introduced to the media. Overall, the acute toxic effects of $\mathrm{TiO}_{2}$ were found to be low, with most effects not showing a clear dosageeffect relationship (Aslani et al. 2014; Li et al. 2015).

\section{Background to Sorghum bicolor (L.) Moenech}

Sorghum bicolor (L.) Moenech (Referred to as Sorghum herein), is the $5^{\text {th }}$ largest cereal crop in the world, and is grown on over 42.8 million hectares (Ha) worldwide (Prasad \& Staggenborg, 2009). Sorghum is an annual monocot grass $\mathrm{C}_{4}$ crop plant that was primarily cultivated in arid and semi-arid regions that are drought-prone, which has helped various sorghum cultivars develop the ability to produce high yields under water stressed conditions (Jagtap et al. 1998; Gerik et al. 2003). Sorghum is a staple crop for over 500 million people worldwide, has a high nutrient content, and is also gluten-free, which can help provide a staple food source for many people with Celiac's disease (Prasad \& Staggenborg, 2009). Sorghum is tolerant to a wide range of stresses including drought and nitrogen stress and can still produce a relatively high yield in low nutrient and water conditions, which also makes it a viable plant for biofuel production (Pandey et al. 2018). High light intensities, high temperatures, and water stress are all known the be factors that inhibit plant growth and crop productivity (Jagtap et al. 1998). In addition to its use as a food source, Sorghum has a wide range of uses including brewing, fodder, feed, forage, and diesel biofuel. In the US and Australia, sorghum is mainly 
grown as feed for cattle and as a biofuel source, and in India and African countries it is mainly grown for human consumption.

\subsection{Physiology of Sorghum}

Sorghum takes approximately 5 to 10 days to emerge from the planting date depending on growth conditions of the soil temperature and moisture content, the depth of planting, and seed vigor (Gerik et al. 2003; Prasad \& Staggenborg, 2009). Sorghum generally prefers warm, moist soils from $21^{\circ} \mathrm{C}$ to $35^{\circ} \mathrm{C}\left(70^{\circ} \mathrm{F}\right.$ to $\left.95^{\circ} \mathrm{F}\right)$ at $\mathrm{pH}$ levels between 6.5 to 7.0 for optimal germination and emergence, while cool, wet soils with acidic soils lower than 5.7 can decrease growth and promote disease development (Gerik et al. 2003; Prasad \& Staggenborg, 2009). After emergence, sorghum develops through three main growth stages (GS I, GS II, and GS III), with each stage taking approximately 32 to 35 days to pass through (Gerik et al. 2003). GS I is characterized by vegetative growth and the development of structures such as leaves and tillers to support grain formation, with hybrids having more leaves taking longer to fully mature (Gerik et al. 2003). GS II is characterized by the formation of reproductive structures of the panicle and when the maximum number of seeds per plant is set. This is the most critical period for grain production, as approximately $70 \%$ of the final grain yield of sorghum is attributed to the seed number per plant (Gerik et al. 2003). GS III is known as the grain filling stage, which begins with flowering and continues until the accumulation of dry matter in the grain stops. Several days after the panicle emerges, flowering begins and is signaled by yellow anthers emerging from the top of the panicle and continuing downwards (Gerik et al. 2003). 


\subsection{Research Goals and Questions}

My research aims to understand the effects that $\mathrm{TiO}_{2}$ ENPs have on Sorghum bicolor by observing the effects that various concentrations of $\mathrm{TiO}_{2}$ have on the growth and physiology of sorghum through measuring germination rates, gas exchange rates, and biomass of plants grown in agar media for 14 day and in soil to full maturity. A previous study by Lee W.M. et al. (2011) used silver nanoparticles (Ag-NPs) with sorghum, and the results indicated that there was a significant decrease in the overall biomass and nitrogen uptake with increasing concentrations of Ag-NPs, and slight necrosis in the root tissue was observed. To my knowledge there have been no studies on the effects of $\mathrm{TiO}_{2}$ ENPs on sorghum, and I hypothesize that growth will be enhanced in juvenile plants with increasing concentrations of the ENP but may prove toxic to plants grown to full maturity.

I addressed three questions. First, how increasing concentrations of $\mathrm{TiO}_{2}$ affect seed germination rate? I hypothesized that there would be no change in the germination rate due to ENP applications. Second, is growth and gas exchange rates of sorghum grown for 14 days in agar affected by increasing $\mathrm{TiO}_{2}$ concentrations? I hypothesized there would be an increase in the growth of the juvenile plants, although plants grown to full maturity may see negative effects, and that there would be a slight increase in gas exchange rates with increasing $\mathrm{TiO}_{2}$ concentrations for juvenile plants. Third, is biomass accumulation of sorghum grown to full maturity in a greenhouse affected by increasing $\mathrm{TiO}_{2}$ concentrations? I hypothesized that increasing $\mathrm{TiO}_{2}$ concentrations would negatively affect sorghum. 


\section{Methods}

\subsection{Overview}

Two different experiments were conducted to test the effects of Titanium dioxide nanoparticles on the growth and physiology of wild type Sorghum bicolor (L.) Moenech. The first experiment was conducted on sorghum seedlings grown for 14 days in agar media, with 4 trials in total, and the second experiment was conducted on sorghum grown to full maturity in soil pots. I applied concentrations of 5, 10, 20, and $40 \mu \mathrm{g} / \mathrm{ml}$, plus a control in agar media, and concentrations of $100,200,500$, and $1000 \mathrm{mg} / \mathrm{kg}$ to dry soil, plus a control, in soil pots.

$\mathrm{TiO}_{2}$ nano powder (anatase, $99.5 \%$ purity, $15 \mathrm{~nm}$ diameter, obtained from US Research Nanomaterials, Inc.) was suspended in distilled water at $1 \mu \mathrm{g} / \mathrm{ml}$; note that the nanoparticles were handled according to training protocols provided by Jordan Valley Innovation Center. Sorghum seeds were provided by the Donald Danforth Plant Science Center.

\subsection{In vitro Experiments; Germination, Growth, and Physiology}

Sorghum bicolor seeds were sterilized by placing them in a sterilization chamber in a fume hood. In a beaker, $100 \mathrm{ml}$ bleach and $3 \mathrm{ml}$ Hydrochloric acid $(\mathrm{HCl})$ were mixed under the sterilization chamber, and seeds were kept in the chamber under the fume hood for three hours while exposed to the chlorine gas.

For each trial, media was prepared for 20 petri dishes. In $10250 \mathrm{ml}$ flasks, Agar (1.0g) was added into each of 5 flasks, while distilled water was added to the other 5 flasks. $25 \mathrm{ml}$ of distilled water was added to flasks corresponding to control petri dishes, and at; $24.38 \mathrm{ml}, 23.75$, 22.50, and $20.00 \mathrm{ml}$ for the flasks corresponding to the petri dishes of nanoparticle 
concentrations of $5,10,20$, and $40 \mu \mathrm{g} / \mathrm{ml}$, respectively. In a separate beaker, 3-

Morpholinopropane-1-sulfonic acid (MOPS) buffer (0.63g), and MS salts (2.71g) were dissolved in $375 \mathrm{ml}$ of distilled water. The $\mathrm{pH}$ of the solution was adjusted to 7.0 by adding $100 \mathrm{mM} \mathrm{KOH}$ and distilled water with a final volume up to $500 \mathrm{ml}$. The solution $(100 \mathrm{ml})$ was added to each of the flasks containing agar. All 10 flasks were autoclaved at $121{ }^{\circ} \mathrm{C}$ for 20 minutes. Agar Flasks were placed in a warm water bath set at $55^{\circ} \mathrm{C}$ to prevent agar from solidifying. After 2 minutes of sonication, nanoparticle suspension was added to the flasks containing water at volumes of $0.13,0.25,0.50$, and $1.00 \mathrm{ml}$, to flasks corresponding to $5,10,20$, and $40 \mu \mathrm{g} / \mathrm{ml}$, respectively. Flasks with unsterilized nanoparticles were supplemented for two of the replicates with a fungicide ( $250 \mu \mathrm{l}$ of Amphotericin B) and a bactericide ( $25 \mu \mathrm{l}$ of carbenicillin) to prevent bacterial or fungal contamination. Two additional replicates did not contain Amphotericin B and carbenicillin to observe if $\mathrm{TiO}_{2}$ nanoparticles had additional antibacterial properties. The flasks were sonicated, and the flasks containing agar was poured into the flasks containing the mixed nanoparticles with distilled water and were held in the sonicator for 2 minutes to ensure even distribution. After the sonication, the flask composition was distributed evenly across 5 petri dishes for each of the treatments and left to cool at room temperature.

Four seeds were evenly placed onto each of the 20 petri dishes. The petri dishes were sealed with parafilm and placed in a refrigerator. After 3 days, the petri dishes were taken out of the refrigerator and the parafilm removed. The petri dishes were placed into a growth chamber (Conviron Model Adaptis A1000-AR Chamber) at $29^{\circ} \mathrm{C}$, photosynthetically active radiation of $500 \mu \mathrm{mol} \mathrm{m} \mathrm{s}^{-1}, 15$-hours light and 9-hours night cycle at $72 \%$ humidity. Petri dishes were rotated randomly each day within the growth chamber to avoid potential position effects. Water was added to the medium daily to prevent desiccation. Then, the number of seedlings germinated 
was recorded daily, and gas exchange data were collected after 14 days of growth in the chambers. The experiment was repeated 4 times, with each repeat treated as trial number for statistical analysis.

Gas exchange was measured using a LI-6400 Portable Photosynthesis System (Licor, Linco) equipped with a $6 \mathrm{~cm}^{2}$ leaf chamber. The measurements were recorded at saturated photosynthetically active radiation (PAR), which was $1000 \mu \mathrm{mol} \mathrm{m}^{-2} \mathrm{~s}^{-1}$. Flow rate in chamber was set to $400 \mu \mathrm{mol} \mathrm{s}{ }^{-1}$ and fan speed was set at high. Leaves were set in the chamber and area reading was adjusted for each leaf due to varying sizes. Leaf area and root area was measured visually for two of the replicates by aligning seedlings on a $1 \mathrm{~cm}^{2}$ grid and taking photos. Further analysis of leaf area was conducted by superimposing additional grid with 25 boxes for each 1 $\mathrm{cm}^{2}$ and visually observing how often the shoots and roots cross each box. For chlorophyll content, random leaves were measured non-destructively using a SPAD Chlorophyll Content Meter (Apogee Instruments, model MC-100). Finally, the fresh weight of the shoots and the roots were measured, followed by the dry weight of the roots and shoots after 3 days of drying. The second replicate had a malfunction in the fan of the leaf drying oven which caused the leaves to get burned, therefore, no dry weights were recorded

\subsection{Soil Experiment: Growths}

I planted Sorghum bicolor seeds in 2.25 -inch square pots in a greenhouse $\left(27^{\circ} \mathrm{C}, 72 \%\right.$ humidity) and allowed seeds to germinate. Once seeds had germinated, I filled 2.5-gallon round pots with $1.276 \mathrm{~kg}$ dry soil and transferred the seedlings to the larger pots. Six replicates were prepared with no additional treatments added, and six replicates of $\mathrm{TiO}_{2}$ concentrations of 100, 200, 500, and $1000 \mathrm{mg} \mathrm{TiO}_{2} / \mathrm{kg}$ dry soil were prepared. I dissolved 0.128, 0.255, 0.638, and 
$1.276 \mathrm{~g}$ of $\mathrm{TiO}_{2}$ nano powder into $200 \mathrm{ml}$ of distilled water and applied the mixture to each replicate of the $100,200,500$, and $1000 \mathrm{mg} \mathrm{TiO}_{2} / \mathrm{kg}$ dry soil treatment pots. Pots were randomly rotated weekly to avoid effects of environmental variation within the greenhouse. Pots were watered daily and fertilized using Hoagland's complete nutrient solution weekly.

Gas exchange data was to be measured during the $3^{\text {rd }}$ and $4^{\text {th }}$ months of growth at full maturity, but a combination of aphid infestation and a pathogen infection disrupted the measurements. In response, a damage assessment assay was performed visually to observe the damage done to leaf area, flowering head emergence, inhibition of water uptake, and plant death as a function of $\mathrm{TiO}_{2}$ concentrations. Other variables observed visually include number of leaves, stems, tillers, flowering heads, and biomass of the roots, shoots, and panicle.

\subsection{Statistical Analysis}

Data were analyzed using statistical software Rstudio version 3.5.1. For the petri dish experiment, I used ANOVA to examine treatment effects of $\mathrm{TiO}_{2}$ nanoparticles on the germination rate, dry weight (of roots and shoots), gas exchange rates (photosynthetic rate, transpiration rates, and instantaneous water use efficiency measured at $1000 \mu \mathrm{mol} \mathrm{m}^{-2} \mathrm{~s}^{-1}$ ), percent moisture, root/shoot ratio, and root area of Sorghum bicolor a priori. Gas exchange rate data were analyzed post priori as repeated measures due to data from final trial being discarded. Trial number, treatment applications, and bactericide were treated as fixed effect factors. The interactions between treatment and trial number were also tested. In trial 4, only biomass accumulation data were analyzed. Data are presented as mean \pm standard error of mean. Tukey's test was performed for pairwise comparisons when main treatment effects in the ANOVA were 
statistically significant at $p<0.05$. Any analysis relating to dry weight biomass and water content has discarded data from trial two because of burned plants.

For the soil experiment, I used ANOVA to examine treatment effects of $\mathrm{TiO}_{2}$ nanoparticles on the number of stems, leaves, tassel heads, tillers, and biomass (dry weight of roots, shoots, and tassels). Tukey's test was performed for pairwise comparisons when main treatment effects in the ANOVA were statistically significant at $p<0.05$. ANOVA tables can be found in the Appendix.

When reporting results, I included the response variables that were significant affects by treatment. All reported values for agar media experiment are mean values ( $\mathrm{n}=5$ per treatment). All reported values for soil media experiment are mean values ( $\mathrm{n}=6$ per treatment). 


\section{RESULTS}

\subsection{Effect of $\mathrm{TiO}_{2}$ Nanoparticle Treatments on Seedling Germination, Biomass, and Root Physiology of Sorghum bicolor grown in Agar Media}

There were no differences in mean germination rate values between controls and $\mathrm{TiO}_{2}$ treatments (Table 1). Germination rates varied between 70 to $86 \%$, which is consistent with known germination rates for this wild type of sorghum (Burow et al. 2014).

There were no differences in mean full plant, shoot, or root dry weight values between controls and $\mathrm{TiO}_{2}$ treatments (Figure 1). The non-statistically significant trends would probably not be changed by increasing sample size for whole plants $(p=0.60)$ and roots $(p=0.33)$, but root mass was close to being significant $(\mathrm{p}=0.08)$. Treatments of $5,10,20$ and $40 \mu \mathrm{g} / \mathrm{ml}$ had lower root weights by $20.4,27.2,23.9$, and 26.1 percent respectively, compared to controls.

There were no differences in mean root length and root area values between controls and $\mathrm{TiO}_{2}$ treatments (Table 1). Root length varied between 7.8 and $4.9 \mathrm{~cm}$. Treatments of 5, 10, 20, and $40 \mu \mathrm{g} / \mathrm{ml}$ had root lengths that were $16.9,5.61,20.0$, and 37.5 percent shorter, respectively, compared to controls. Treatments of $5,10,20$, and $40 \mu \mathrm{g} / \mathrm{ml}$ had root areas that were 19.6, 20.6, 29.3, and 40.9 percent lower, respectively, than controls.

\subsection{Effect of $\mathrm{TiO}_{2}$ Nanoparticle Treatments on Gas Exchange in Sorghum bicolor grown in}

\section{Agar Media}

There were no differences in mean photosynthetic rate $\left(\mathrm{A}_{\max }\right)$ values (Table 2$)$.

Photosynthetic rates ranged between a high of $7.5 \mathrm{~mol} \mathrm{CO}_{2} \mathrm{~m}^{-2} \mathrm{~s}^{-1}$ in the control and low of 5.13 $\mathrm{mol} \mathrm{CO} 2 \mathrm{~m}^{-2} \mathrm{~s}^{-1}$ in the $10 \mu \mathrm{g} / \mathrm{ml}$ treatment. These values are low for this species and $\mathrm{C} 4$ plants in 
general and it may be that light levels were not saturating (Kidambi et al. 1990; Girma \& Krieg, 1992). Nonetheless, it is not surprising that low non-significant differences in photosynthetic rates were consistent with biomass accumulation of seedlings (Table 1).

There were no differences in mean transpiration rate $\left(\mathrm{E}_{\max }\right)$ values between controls and $\mathrm{TiO}_{2}$ treatments (Table 2). The transpiration rates were lower compared to those reported in the literature (Balota et al. 2008), and ranged from $7.9 \mathrm{~mol} \mathrm{H}_{2} \mathrm{O} \mathrm{m}^{-2} \mathrm{~s}^{-1}$ in the control and $12.5 \mathrm{~mol}$ $\mathrm{H}_{2} \mathrm{O} \mathrm{m}^{-2} \mathrm{~s}^{-1}$ in the $5 \mu \mathrm{g} / \mathrm{ml}$ treatment. The growth in media in petri dishes that were kept moist could account for the high transpiration rates. There were also a lot of variation in rates across individuals, but particularly in the $5 \mu \mathrm{g} / \mathrm{ml}$ treatment. Percent differences from controls was often very high; for example, treatments of $5,10,20$, and $40 \mu \mathrm{g} / \mathrm{ml}$ had higher transpiration rates by 57.6, 19.6, 31.6, and 10.4 percent compared to controls.

There was evidence that the concentrations of $\mathrm{TiO}_{2}$ nanoparticles affected the instantaneous water use efficiency ( $\left.\mathrm{A}_{\max } / \mathrm{E}\right)$ of $S$. bicolor grown in agar media (Table 2). Patterns in response to different concentration levels were consistent. Treatments of 5 and $40 \mu \mathrm{g} / \mathrm{ml}$ had lower water use efficiency rates by 44.6 and 24.8 percent respectively, compared to controls, although differences were not significant. Treatments of 10 and $20 \mu \mathrm{g} / \mathrm{ml}$ had significantly lower $(\mathrm{p}<0.024)$ instantaneous water use efficiency rates by 52.7 and 47.4 percent respectively, compared to controls. 


\subsection{Effects of $\mathrm{TiO}_{2}$ Nanoparticle Treatments on Growth, Damage, and Biomass of Sorghum bicolor grown in Soil}

There was evidence that concentrations of $\mathrm{TiO}_{2}$ nanoparticles marginally affected the number of stems and leaves of $S$. bicolor grown in soil $(p=0.055$ and $p=0.076$, respectively) (Table 3). Some patterns in response to different concentration levels were consistent.

Treatments of $100 \mathrm{mg} / \mathrm{kg}$ dry soil had a lower number of stems by 12.0 percent compared to controls. Treatments of 200,500 , and $1000 \mathrm{mg} / \mathrm{kg}$ dry soil had a higher number of stems by 5.3, 65.4, and 110.5 percent respectively, compared to controls. Treatments of 100, 200, and 500, and $1000 \mathrm{mg} / \mathrm{kg}$ dry soil had higher numbers of leaves by $15.2,27.3,60$, and 90.9 percent respectively, compared to controls.

There were no differences in mean number of tassel heads, number of tillersand percent damage values between controls and $\mathrm{TiO}_{2}$ treatments (Table 3 ). There were no differences in dry weight biomass accumulation of shoots, roots, and tassel heads values between controls and $\mathrm{TiO}_{2}$ treatments (Figure 2). Some patterns in response to different concentration levels were consistent. There were instances where the percent difference between the control mean and a treatment mean was very high, indicating that sample sizes might have been too low and variation between individuals was too high to detect differences.

Treatments of 500 and $1000 \mathrm{mg} / \mathrm{kg}$ dry soil had a number of tillers that were $109.0 \%$ and 49.3\% greater than controls, respectively. The number of tillers falls within expected values found from the literature (Foster et al. 1994). Treatments of 500 and $1000 \mathrm{mg} / \mathrm{kg}$ dry soil had dry weight of shoots $42.0 \%$ and $68.3 \%$ greater than controls, respectively.

Treatments of 500 and $1000 \mathrm{mg} / \mathrm{kg}$ dry soil had ratio of number of stems to tassel heads that were $45.0 \%$ and $100.0 \%$ greater than controls, respectively. Treatments of 500 and 1000 
$\mathrm{mg} / \mathrm{kg}$ dry soil had ratio of number of tillers to stems that were $56.8 \%$ and $29.4 \%$ greater than controls, respectively. Treatments of 200 and $1000 \mathrm{mg} / \mathrm{kg}$ dry soil had ratio of number of stems to tillers that were $15.0 \%$ and $29.3 \%$ greater than controls, respectively. Treatments of 100 and $500 \mathrm{mg} / \mathrm{kg}$ dry soil had ratio of number of stems to tassel heads that were $11.6 \%$ and $20.7 \%$ lower than controls, respectively. These values indicate that higher concentrations of $\mathrm{TiO}_{2}$ may have altered the allocation of biomass to different parts of the plants. 


\section{DISCUSSION}

There have been several studies on the effects of $\mathrm{TiO}_{2}$ ENPs on the growth, development, or gas exchange rates of plants (Aslani \& Neumann, 2009; Klaine et al. 2009; Seeger et al. 2019; Kurepa et al. 2010; Jaberzadeh et al. 2013; Mahmoodzadeh et al. 2013; Tang et al. 2013; Li et al. 2015; Vance et al. 2015; Hedge et al. 2016; Siddiqui et al. 2015), but to my knowledge, there have been no studies on the effect of $\mathrm{TiO}_{2}$ ENPs on $S$. bicolor. The results of the studies listed above range from $\mathrm{TiO}_{2}$ ENPs having mildly positive effects on plant growth, to neutral effects on plant growth, to negative effects on plant growth, with no seemingly obvious pattern. A study by Lee et al. (2011) reported negative effects of silver quantum dots on sorghum, although direct comparisons are not possible due to the significantly larger inherent negative qualities silver has on plants compared to titanium. The methods followed for this experiment mirror those of Lee et al. (2011) in concentrations used for agar media and soil concentrations of the ENP.

I found that there was a significant difference in the instantaneous water use efficiency (p $=0.024)$ for treatments of $\mathrm{TiO}_{2}$ ENPs of 10 and $20 \mu \mathrm{g} / \mathrm{ml}$, while all other gas exchange data were not significant. This is similar to results found by Asli \& Neumann, (2009), who reported a reduction in hydraulic conductivity and a decrease in cell wall pore size of Zea mays when $\mathrm{TiO}_{2}$ ENPs were applied. Other reasons for a significant difference in the water use efficiency may include damage to chlorophyll and thylakoid membranes of S. bicolor due to $\mathrm{TiO}_{2} \mathrm{ENPs}$ generating excess ROS. Excess generation of ROS can also cause changes in hormonal responses to stress and inflammatory responses, both of which may affect the development of plants (Klaine et al. 2008). I found no significant effects of $\mathrm{TiO}_{2}$ applications on the biomass of $S$. bicolor grown in agar media for 14 days or on the biomass or differences in damage done to $S$. 
bicolor grown in soil to full maturity. This is similar to results found by Seeger et al. (2009); Tang et al. (2013); Aslani et al. (2014); and Li et al. (2015), who all reported either minute differences or no observable differences in plant growth due to applications of $\mathrm{TiO}_{2} \mathrm{ENPs}$. Although not found to be significant, visual observations of juvenile sorghum seedlings seemed to indicate concentrations of 20 and $40 \mu \mathrm{g} / \mathrm{ml} \mathrm{TiO}_{2}$ resulted in an increase in growth and biomass compared to the control and concentrations of 5 and $10 \mu \mathrm{g} / \mathrm{ml} \mathrm{TiO}_{2}$.

Due to unforeseen issues associated with instrument malfunction and insect outbreaks, sample sizes for various measurements are very low. A damage assay was visually completed to assess the level of damage done to different treatments of $\mathrm{TiO}_{2}$ on sorghum grown in a greenhouse.

Future studies on the effects of $\mathrm{TiO}_{2}$ on sorghum are needed to analyze the uptake and translocation of the ENP to gather information on the mechanisms behind its movement in the roots and leaves. Studies on the sedimentation and aggregation of $\mathrm{TiO}_{2}$ in soil will be needed to determine its ability to transform in media. Studies on the mechanisms of ENP uptake and translocation by plants are needed to determine if ENPs can be found in leaf and grain tissue, and if tropic transfer is possible. Molecular assays may help determine S. bicolor responses to stress from excess ROS generation and hormonal response changes due to ENPs. Studies on the intergenerational effects $\mathrm{TiO}_{2}$ ENPs can have on S. bicolor are needed to determine possible long-term exposure effects. 


\section{REFERENCES}

Aslani, F., Bagheri, S., Muhd Julkapli, N., Juraimi, A. S., Hashemi, F. S. G., \& Baghdadi, A. (2014). Effects of engineered nanomaterials on plants growth: an overview. The Scientific World Journal, 2014.

Asli, S., \& Neumann, P. M. (2009). Colloidal suspensions of clay or titanium dioxide nanoparticles can inhibit leaf growth and transpiration via physical effects on root water transport. Plant, cell \& environment, 32(5), 577-584.

Auffan, M., Rose, J., Bottero, J. Y., Lowry, G. V., Jolivet, J. P., \& Wiesner, M. R. (2009). Towards a definition of inorganic nanoparticles from an environmental, health and safety perspective. Nature nanotechnology, 4(10), 634.

Balota, M., Payne, W. A., Rooney, W., \& Rosenow, D. (2008). Gas exchange and transpiration ratio in sorghum. Crop Science, 48(6), 2361-2371.

Blind, K., \& Gauch, S. (2009). Research and standardisation in nanotechnology: evidence from Germany. The Journal of Technology Transfer, 34(3), 320-342.

Burow, G., Xin, Z., Hayes, C., \& Burke, J. (2014). Characterization of a multiseeded (msd1) mutant of sorghum for increasing grain yield. Crop Science, 54(5), 2030-2037.

Buzea, C., Pacheco, I. I., \& Robbie, K. (2007). Nanomaterials and nanoparticles: sources and toxicity. Biointerphases, 2(4), MR17-MR71.

Cornelis, G., Ryan, B., McLaughlin, M. J., Kirby, J. K., Beak, D., \& Chittleborough, D. (2011). Solubility and batch retention of $\mathrm{CeO} 2$ nanoparticles in soils. Environmental science \& technology, 45(7), 2777-2782.

Foster, K. R., Miller, F. R., Childs, K. L., \& Morgan, P. W. (1994). Genetic regulation of Development in Sorghum bicolor (VIII. Shoot Growth, tillering, flowering, gibberellin biosynthesis, and phytochrome levels are differentially affected by dosage of the ma3r allele. Plant physiology, 105(3), 941-948.

García, A., Espinosa, R., Delgado, L., Casals, E., González, E., Puntes, V., ... \& Sánchez, A. (2011). Acute toxicity of cerium oxide, titanium oxide and iron oxide nanoparticles using standardized tests. Desalination, 269(1-3), 136-141.

Gerik, T., Bean, B. W., \& Vanderlip, R. (2003). Sorghum growth and development. Texas FARMER Collection. 
Girma, F. S., \& Krieg, D. R. (1992). Osmotic adjustment in sorghum: II. Relationship to gas exchange rates. Plant Physiology, 99(2), 583-588.

Gottschalk, F., Sun, T., \& Nowack, B. (2013). Environmental concentrations of engineered nanomaterials: review of modeling and analytical studies. Environmental pollution, 181, $287-300$.

Hegde, K., Brar, S. K., Verma, M., \& Surampalli, R. Y. (2016). Current understandings of toxicity, risks and regulations of engineered nanoparticles with respect to environmental microorganisms. Nanotechnology for Environmental Engineering, 1(1), 5.

Jaberzadeh, A., Moaveni, P., MOGHADAM, H. R. T., \& Zahedi, H. (2013). Influence of bulk and nanoparticles titanium foliar application on some agronomic traits, seed gluten and starch contents of wheat subjected to water deficit stress. Notulae Botanicae Horti Agrobotanici Cluj-Napoca, 41(1), 201-207.

Jagtap, V., Bhargava, S., Streb, P., \& Feierabend, J. (1998). Comparative effect of water, heat and light stresses on photosynthetic reactions in Sorghum bicolor (L.) Moench. Journal of Experimental Botany, 49(327), 1715-1721.

Jones, M. M., \& Rawson, H. M. (1979). Influence of rate of development of leaf water deficits upon photosynthesis, leaf conductance, water use efficiency, and osmotic potential in sorghum. Physiologia plantarum, 45(1), 103-111.

Keller, A. A., Wang, H., Zhou, D., Lenihan, H. S., Cherr, G., Cardinale, B. J., ... \& Ji, Z. (2010). Stability and aggregation of metal oxide nanoparticles in natural aqueous matrices. Environmental science \& technology, 44(6), 1962-1967.

Kidambi, S. P., Krieg, D. R., \& Rosenow, D. T. (1990). Genetic variation for gas exchange rates in grain sorghum. Plant Physiology, 92(4), 1211-1214.

Klaine, S. J., Alvarez, P. J., Batley, G. E., Fernandes, T. F., Handy, R. D., Lyon, D. Y., ... \& Lead, J. R. (2008). Nanomaterials in the environment: behavior, fate, bioavailability, and effects. Environmental Toxicology and Chemistry: An International Journal, 27(9), 18251851.

Kurepa, J., Paunesku, T., Vogt, S., Arora, H., Rabatic, B. M., Lu, J., ... \& Smalle, J. A. (2010). Uptake and distribution of ultrasmall anatase $\mathrm{TiO} 2$ Alizarin red $\mathrm{S}$ nanoconjugates in Arabidopsis thaliana. Nano letters, 10(7), 2296-2302.

Lee, C. W., Mahendra, S., Zodrow, K., Li, D., Tsai, Y. C., Braam, J., \& Alvarez, P. J. (2010). Developmental phytotoxicity of metal oxide nanoparticles to Arabidopsis thaliana. Environmental Toxicology and Chemistry: An International Journal, 29(3), 669675. 
Lee, W. M., Kwak, J. I., \& An, Y. J. (2012). Effect of silver nanoparticles in crop plants Phaseolus radiatus and Sorghum bicolor: media effect on phytotoxicity. Chemosphere, 86(5), 491-499.

Li, J., Naeem, M. S., Wang, X., Liu, L., Chen, C., Ma, N., \& Zhang, C. (2015). Nano-TiO2 is not phytotoxic as revealed by the oilseed rape growth and photosynthetic apparatus ultrastructural response. PLoS One, 10(12).

Ma, X., Geiser-Lee, J., Deng, Y., \& Kolmakov, A. (2010). Interactions between engineered nanoparticles (ENPs) and plants: phytotoxicity, uptake and accumulation. Science of the total environment, 408(16), 3053-3061.

Mahmoodzadeh, H., Nabavi, M., \& Kashefi, H. (2013). Effect of nanoscale titanium dioxide particles on the germination and growth of canola (Brassica napus). Journal of Ornamental and Horticultural Plants. 3(1), 25-32.

Maurer-Jones, M. A., Gunsolus, I. L., Murphy, C. J., \& Haynes, C. L. (2013). Toxicity of engineered nanoparticles in the environment. Analytical chemistry, 85(6), 3036-3049.

Nel, A., Xia, T., Mädler, L., \& Li, N. (2006). Toxic potential of materials at the nanolevel. Science, 311(5761), 622-627.

Nowack, B., \& Bucheli, T. D. (2007). Occurrence, behavior and effects of nanoparticles in the environment. Environmental pollution, 150(1), 5-22.

Pandey, K., Lahiani, M. H., Hicks, V. K., Hudson, M. K., Green, M. J., \& Khodakovskaya, M. (2018). Effects of carbon-based nanomaterials on seed germination, biomass accumulation and salt stress response of bioenergy crops. PloS one, 13(8).

Prasad, P. V., \& Staggenborg, S. A. (2009). Growth and production of sorghum and millets. Soils, plant growth and crop production, 2.

Rico, C. M., Johnson, M. G., Marcus, M. A., \& Andersen, C. P. (2018). Shifts in N and $\delta 15 N$ in wheat and barley exposed to cerium oxide nanoparticles. NanoImpact, 11, 156-163.

Rico, C. M., Peralta-Videa, J. R., \& Gardea-Torresdey, J. L. (2015). Chemistry, biochemistry of nanoparticles, and their role in antioxidant defense system in plants. Nanotechnology and Plant Sciences, 1-17.

Seeger, E. M., Baun, A., Kästner, M., \& Trapp, S. (2009). Insignificant acute toxicity of TiO2 nanoparticles to willow trees. Journal of Soils and Sediments, 9(1), 46-53.

Sharifi, S., Behzadi, S., Laurent, S., Forrest, M. L., Stroeve, P., \& Mahmoudi, M. (2012). Toxicity of nanomaterials. Chemical Society Reviews, 41(6), 2323-2343. 
Siddiqui, M. H., Al-Whaibi, M. H., Firoz, M., \& Al-Khaishany, M. Y. (2015). Role of nanoparticles in plants. Nanotechnology and Plant Sciences, 19-35.

Tang, Y., Li, S., Qiao, J., Wang, H., \& Li, L. (2013). Synergistic effects of nano-sized titanium dioxide and zinc on the photosynthetic capacity and survival of Anabaena sp. International journal of molecular sciences, 14(7), 14395-14407.

Teszlák, P., Kocsis, M., Scarpellini, A., Jakab, G., \& Körösi, L. (2018). Foliar exposure of grapevine (Vitis vinifera L.) to TiO 2 nanoparticles under field conditions: Photosynthetic response and flavonol profile. Photosynthetica, 56(4), 1378-1386.

Vance, M. E., Kuiken, T., Vejerano, E. P., McGinnis, S. P., Hochella Jr, M. F., Rejeski, D., \& Hull, M. S. (2015). Nanotechnology in the real world: Redeveloping the nanomaterial consumer products inventory. Beilstein journal of nanotechnology, 6(1), 1769-1780.

Ze, Y., Liu, C., Wang, L., Hong, M., \& Hong, F. (2011). The regulation of TiO 2 nanoparticles on the expression of light-harvesting complex II and photosynthesis of chloroplasts of Arabidopsis thaliana. Biological trace element research, 143(2), 1131-1141. 
Table 1. Seedling germination rate, plant dry weight biomass, root length, and root area of Sorghum bicolor plants grown for 14 days in agar media. The indicated variables for growth in agar media are not significantly different $(\mathrm{p}<0.05)$ between treatments. Values are Mean \pm SE $(n$ $=100)$

\begin{tabular}{llllll}
\hline Variable & Control & $5 \mu \mathrm{g} / \mathrm{ml}$ & $10 \mu \mathrm{g} / \mathrm{ml}$ & $20 \mu \mathrm{g} / \mathrm{ml}$ & $40 \mu \mathrm{g} / \mathrm{ml}$ \\
\hline Germination Rate (\%) & $77.5 \pm$ & $71.25 \pm$ & $70.0 \pm$ & $81.25 \pm$ & $85.63 \pm$ \\
& 3.67 & 6.50 & 1.77 & 9.16 & 5.63 \\
& & & & & \\
Root Length (cm) & $7.83 \pm$ & $6.51 \pm$ & $7.39 \pm$ & $6.27 \pm$ & $4.89 \pm$ \\
& 0.77 & 1.44 & 1.06 & 1.08 & 0.13 \\
& & & & & \\
Root Area $\left(\mathrm{cm}^{2}\right)$ & $9.12 \pm$ & $7.33 \pm$ & $7.24 \pm$ & $6.45 \pm$ & $5.39 \pm$ \\
& 0.72 & 0.89 & 0.92 & 0.86 & 0.08 \\
& & & & & \\
\hline
\end{tabular}

Table 2. Photosynthetic rate, transpiration rate, and water use efficiency of sorghum grown for 14 days in agar media.

\begin{tabular}{|c|c|c|c|c|c|}
\hline Variable & Control & $5 \mu \mathrm{g} / \mathrm{ml}$ & $10 \mu \mathrm{g} / \mathrm{ml}$ & $20 \mu \mathrm{g} / \mathrm{ml}$ & $40 \mu \mathrm{g} / \mathrm{ml}$ \\
\hline${ }^{\mathrm{a}} \mathrm{A}_{\max }\left(\mu \mathrm{mol} \mathrm{CO} 2 \mathrm{~m}^{-2} \mathrm{~s}^{-1}\right)$ & $\begin{array}{l}7.53 \pm \\
0.92\end{array}$ & $\begin{array}{l}5.74 \pm \\
2.07\end{array}$ & $\begin{array}{l}5.13 \pm \\
2.04\end{array}$ & $\begin{array}{l}6.36 \pm \\
1.54\end{array}$ & $\begin{array}{l}7.25 \pm \\
1.60\end{array}$ \\
\hline${ }^{\mathrm{b}} \mathrm{E}_{\max }\left(\mathrm{mol} \mathrm{H} \mathrm{H}_{2} \mathrm{O} \mathrm{m}^{-2} \mathrm{~s}^{-1}\right)$ & $\begin{array}{l}7.91 \pm \\
0.91\end{array}$ & $\begin{array}{l}12.47 \pm \\
3.08\end{array}$ & $\begin{array}{l}9.46 \pm \\
0.35\end{array}$ & $\begin{array}{l}10.41 \pm \\
0.58\end{array}$ & $\begin{array}{l}8.73 \pm \\
0.72\end{array}$ \\
\hline $\begin{array}{l}{ }^{\mathrm{c}} \mathrm{A}_{\max } / \mathrm{E} \\
\left(\mu \mathrm{mol} \mathrm{CO} \mathrm{Col}^{-1} \mathrm{H}_{2} \mathrm{O}\right)\end{array}$ & $\begin{array}{l}0.96 \pm \\
0.14 \mathrm{a}\end{array}$ & $\begin{array}{l}0.56 \pm \\
0.24 \mathrm{a}, \mathrm{b}\end{array}$ & $\begin{array}{l}0.55 \pm \\
0.24 b\end{array}$ & $\begin{array}{l}0.60 \pm \\
0.13 \mathrm{~b}\end{array}$ & $\begin{array}{l}0.86 \pm \\
0.23 \mathrm{a}, \mathrm{b}\end{array}$ \\
\hline
\end{tabular}

${ }^{\mathrm{a}} \mathrm{A}_{\max }$; photosynthetic rate at $\mathrm{PAR}=1000 \mu \mathrm{mol} \mathrm{m} \mathrm{m}^{-2} \mathrm{~s}^{-1},{ }^{\mathrm{b}} \mathrm{E}_{\max }$; transpiration rate at $\mathrm{PAR}=1000$ $\mu \mathrm{mol} \mathrm{m} \mathrm{s}^{-2} \mathrm{~s}^{-1}{ }^{\mathrm{c}} \mathrm{A}_{\max } / \mathrm{E}$; instantaneous water use efficiency at $\mathrm{PAR}=1000 \mu \mathrm{mol} \mathrm{m} \mathrm{s}^{-2}$. The letters $(\mathrm{a} / \mathrm{b})$ indicate significant differences $(\mathrm{p}<0.05)$ between treatments. Values are Mean $\pm \mathrm{SE}$ $(n=75)$. 
Table 3. Growth response of S. bicolor grown in soil. The variables are not significantly different $(\mathrm{p}<0.05)$ between treatments. Values are Mean \pm SE $(n=100)$

\begin{tabular}{llllll}
\hline Variable & Control & $100 \mathrm{mg} / \mathrm{kg}$ & $200 \mathrm{mg} / \mathrm{kg}$ & $500 \mathrm{mg} / \mathrm{kg}$ & $1000 \mathrm{mg} / \mathrm{kg}$ \\
\hline Number of Stems & $1.33 \pm$ & $1.17 \pm$ & $1.4 \pm$ & $2.2 \pm$ & $2.8 \pm$ \\
& 0.33 & 0.17 & 0.25 & 0.58 & 0.58 \\
& & & & & \\
& & & & & \\
& & & & \\
Number of Tassel & $1.33 \pm$ & $1.17 \pm$ & $1.2 \pm$ & $1.2 \pm$ & $1.4 \pm$ \\
Heads & 0.33 & 0.17 & 0.2 & 0.2 & 0.51 \\
& & & & & \\
Number of Tillers & $0.67 \pm$ & $0.67 \pm$ & $0.6 \pm$ & $1.4 \pm$ & $1 \pm$ \\
& 0.33 & 0.33 & 0.25 & 0.68 & 0.55 \\
& & & & & \\
Number of Leaves & $11 \pm$ & $12.67 \pm$ & $14 \pm$ & $17.6 \pm$ & $21 \pm$ \\
& 1.0 & 0.71 & 1.05 & 3.14 & 3.96 \\
& & & & & \\
$\begin{array}{l}\text { Damage } \\
\text { (\% of plant) }\end{array}$ & $50 \pm$ & $54.17 \pm$ & $50 \pm$ & $76.67 \pm$ & $61.67 \pm$ \\
& 0.0 & 7.68 & 2.28 & 8.07 & 10.01 \\
\hline
\end{tabular}




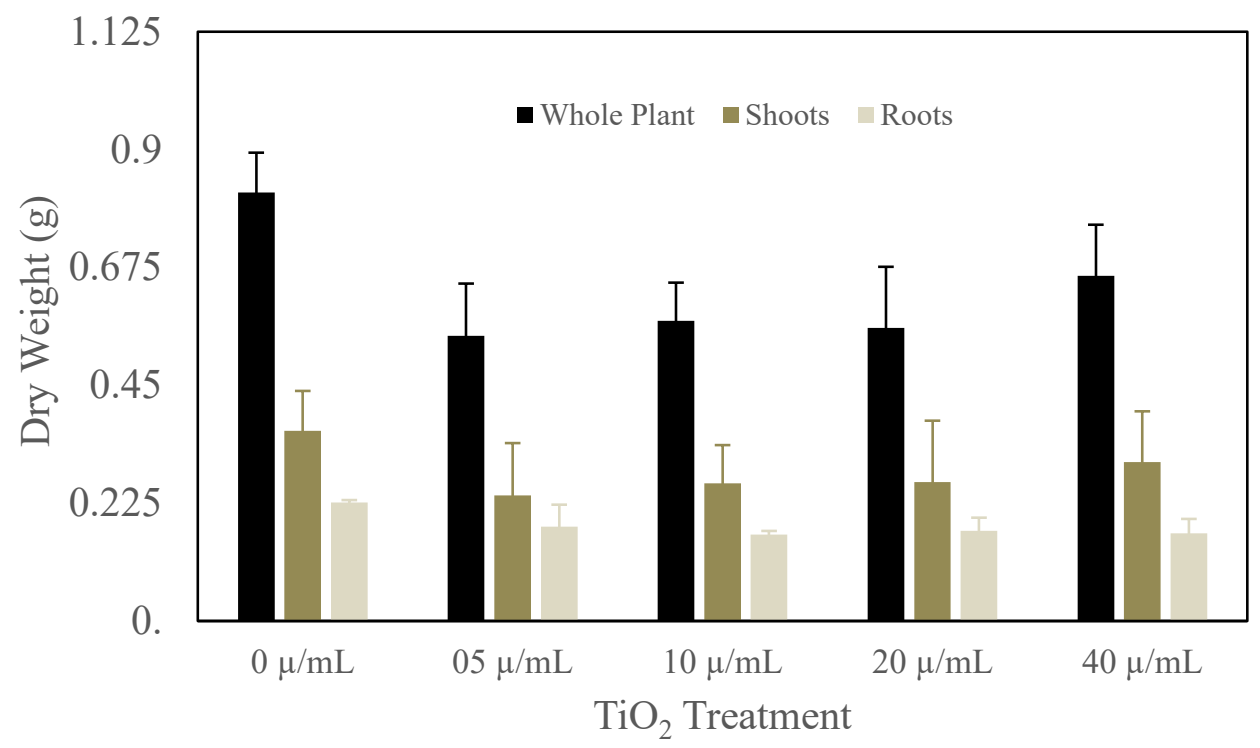

Figure 1. Mean dry weight of full plant, shoots, and roots of S. bicolor in controls and different concentrations of $\mathrm{TiO}_{2}$ nanoparticle treatments after 14 days of growth in agar media. The error bar is the mean of standard error for each treatment $(n=75)$.

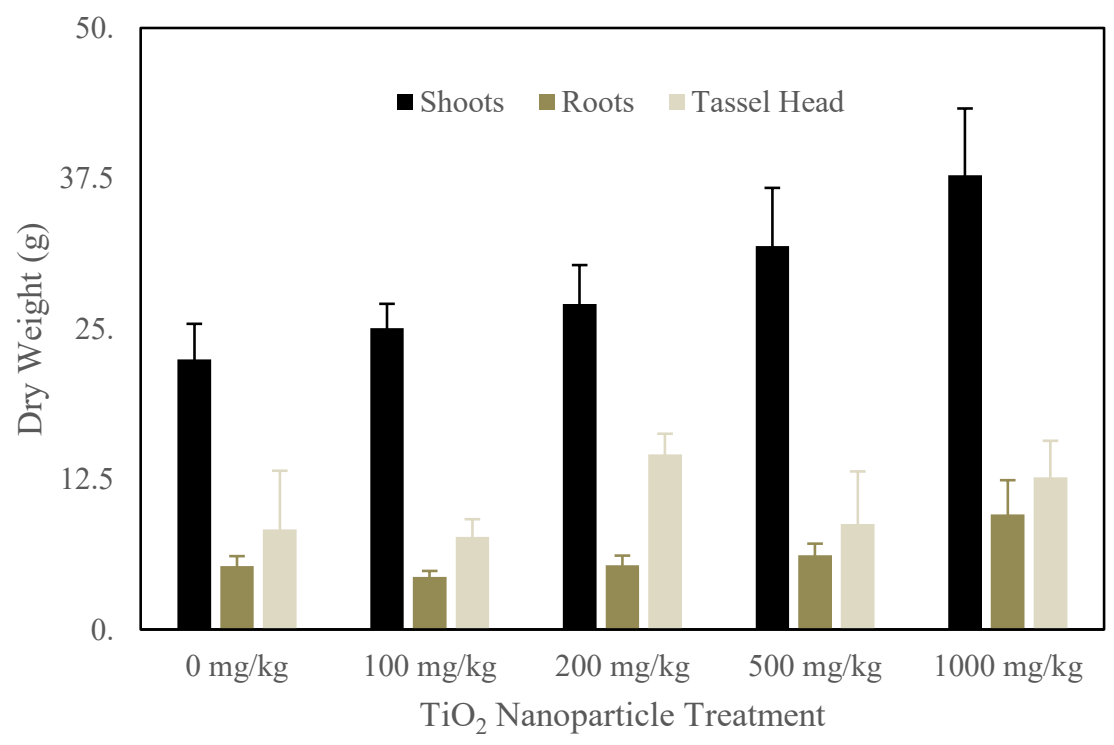

Figure 2. Mean dry weight of shoots, roots, and tassel head of S. bicolor in controls and different concentrations of $\mathrm{TiO}_{2}$ nanoparticle treatments after growing to full maturity in soil. The error bar is the mean of standard error for each treatment $(n=36)$. 


\section{APPENDIX: ANOVA TABLES}

Germination rates of $S$. bicolor seeds grown in agar media for 14 days. The test used for ANOVA is general linear model with a significant level $\mathrm{p}$-value $<0.05$ and sample size $(\mathrm{n}=$ 100). $\mathrm{TiO}_{2}$ treatments $(0,5,10,20$, and $40 \mu \mathrm{g} / \mathrm{ml})$ and Trial (1-4) were treated as fixed factors. **indicates a significance level of $\mathrm{p}<0.005$

\begin{tabular}{lccccc}
\hline Source & Df & Adj SS & Adj MS & F-Value & P-Value \\
\hline Treatment & 4 & 698.7 & 174.7 & 3.055 & 0.596 \\
Trial & 3 & 1405.9 & 468.6 & 8.195 & $0.0031^{* *}$ \\
Residuals & 12 & 686.2 & 57.2 & & \\
\hline
\end{tabular}

ANOVA table for full plant dry weight of S. bicolor grown in agar media for 14 days. The test used for ANOVA is general linear model with a significant level p-value $<0.05$ and sample size $(\mathrm{n}=75) . \mathrm{TiO}_{2}$ treatments $(0,5,10,20$, and $40 \mu \mathrm{g} / \mathrm{ml})$ and Trial $(1-3)$ were treated as fixed factors.

\begin{tabular}{lccccc}
\hline Source & Df & Adj SS & Adj MS & F-Value & P-Value \\
\hline Treatment & 4 & 0.1554 & 0.03886 & 1.269 & 0.358 \\
Trial & 2 & 0.1097 & 0.05483 & 1.791 & 0.228 \\
Residuals & 8 & 0.2449 & 0.03062 & & \\
\hline
\end{tabular}


ANOVA table for shoot dry weight of $S$. bicolor grown in agar media for 14 days. The test used for ANOVA is general linear model with a significant level $\mathrm{p}$-value $<0.05$ and sample size $(\mathrm{n}=$ 75). $\mathrm{TiO}_{2}$ treatments $(0,5,10,20$, and $40 \mu \mathrm{g} / \mathrm{ml})$ and Trial $(1-3)$ were treated as fixed factors. *** indicates significance level of $\mathrm{p}<0.005$.

\begin{tabular}{llllll}
\hline Source & Df & Adj SS & Adj MS & F-Value & P-Value \\
\hline Treatment & 4 & 0.028 & 0.007 & 3.076 & 0.0825 \\
Trial & 2 & .0897 & 0.0449 & 19.710 & $0.00081^{* * *}$ \\
Residuals & 8 & 0.0182 & 0.0023 & & \\
\hline
\end{tabular}

ANOVA table for root dry weight of $S$. bicolor grown in agar media for 14 days. The test used for ANOVA is general linear model with a significant level $\mathrm{p}$-value $<0.05$ and sample size $(\mathrm{n}=$ 75). $\mathrm{TiO}_{2}$ treatments $(0,5,10,20$, and $40 \mu \mathrm{g} / \mathrm{ml})$ and Trial $(1-3)$ were treated as fixed factors. *indicates significance level of $\mathrm{p}<0.05$

\begin{tabular}{lccccc}
\hline Source & Df & Adj SS & Adj MS & F-Value & P-Value \\
\hline Treatment & 4 & 0.00774 & 0.00193 & 1.371 & 0.326 \\
Trial & 2 & 0.01449 & 0.00724 & 5.136 & $0.0367^{*}$ \\
Residuals & 8 & 0.01129 & 0.00141 & & \\
\hline
\end{tabular}


ANOVA table for root length of $S$. bicolor grown in agar media for 14 days. The test used for ANOVA is general linear model with a significant level $\mathrm{p}$-value $<0.05$ and sample size $(\mathrm{n}=75)$. $\mathrm{TiO}_{2}$ treatments $(0,5,10,20$, and $40 \mu \mathrm{g} / \mathrm{ml})$ and Trial $(1-3)$ were treated as fixed factors.

\begin{tabular}{lccccc}
\hline Source & Df & Adj SS & Adj MS & F-Value & P-Value \\
\hline Treatment & 4 & 10.34 & 2.59 & 0.63 & 0.667 \\
Trial & 1 & 3.54 & 3.54 & 0.87 & 0.405 \\
Residuals & 4 & 16.39 & 4.10 & & \\
\hline
\end{tabular}

ANOVA table for root area of S. bicolor grown in agar media for 14 days. The test used for ANOVA is general linear model with a significant level $\mathrm{p}$-value $<0.05$ and sample size $(\mathrm{n}=75)$. $\mathrm{TiO}_{2}$ treatments $(0,5,10,20$, and $40 \mu \mathrm{g} / \mathrm{ml})$ and Trial (1-3) were treated as fixed factors.

\begin{tabular}{lccccc}
\hline Source & Df & Adj SS & Adj MS & F-Value & P-Value \\
\hline Treatment & 4 & 15.03 & 3.76 & 1.53 & 0.346 \\
Trial & 1 & 1.74 & 1.74 & 0.71 & 0.447 \\
Residuals & 4 & 9.84 & 2.46 & & \\
\hline
\end{tabular}


ANOVA table for transpiration rate; $\mathrm{E}_{\max }$ at light level $\left(\mathrm{PAR}=1000 \mu \mathrm{mol} \mathrm{m} \mathrm{m}^{-2} \mathrm{~s}^{-1}\right)$ of $S$. bicolor grown in agar media for 14 days. The test used for ANOVA is general linear model with a significant level $\mathrm{p}$-value $<0.05$ and sample size $(\mathrm{n}=75) . \mathrm{TiO}_{2}$ treatments $(0,5,10,20$, and 40 $\mu \mathrm{g} / \mathrm{ml})$ and Trial (1-4) were treated as fixed factors.

\begin{tabular}{lccccc}
\hline Source & Df & Adj SS & Adj MS & F-Value & P-Value \\
\hline Treatment & 4 & 37.01 & 9.25 & 1.99 & 0.19 \\
Trial & 2 & 23.06 & 13.01 & 2.80 & 0.12 \\
Residuals & 8 & 37.12 & 4.64 & & \\
\hline
\end{tabular}

ANOVA table for water use efficiency; $\mathrm{A}_{\max } / \mathrm{E}_{\max }$ at light level $\left(\mathrm{PAR}=1000 \mu \mathrm{mol} \mathrm{m} \mathrm{m}^{-2} \mathrm{~s}^{-1}\right)$ of $S$. bicolor grown in agar media for 14 days. The test used for ANOVA is general linear model with a significant level $\mathrm{p}$-value $<0.05$ and sample size $(\mathrm{n}=75)$. TiO 2 treatments $(0,5,10,20$, and 40 $\mu \mathrm{g} / \mathrm{ml})$ and Trial (1-3) were treated as fixed factors. **indicates significance of $\mathrm{p}<0.005$

\begin{tabular}{llllll}
\hline Source & Df & Adj SS & Adj MS & F-Value & P-Value \\
\hline Treatment & 4 & 84.2 & 21.05 & 5.12 & 0.024 \\
Trial & 2 & 143.99 & 71.99 & 17.50 & $0.0012^{* *}$ \\
Residuals & 8 & 32.92 & 4.11 & & \\
\hline
\end{tabular}

ANOVA table for number of stems of S. bicolor grown in soil to full maturity. The test used for ANOVA is general linear model with a significant level $\mathrm{p}$-value $<0.05$ and sample size $(\mathrm{n}=36)$. $\mathrm{TiO}_{2}$ treatments $(0,100,200,500$, and $1000 \mathrm{mg} / \mathrm{kg}$ of dry soil) were treated as a fixed effect factor.

\begin{tabular}{llllll}
\hline Source & Df & Adj SS & Adj MS & F-Value & P-Value \\
\hline Treatment & 4 & 9.658 & 2.1446 & 2.815 & 0.0545 \\
Residuals & 19 & 16.300 & 0.8579 & & \\
\hline
\end{tabular}


ANOVA table for number of leaves of $S$. bicolor grown in soil to full maturity. The test used for ANOVA is general linear model with a significant level $\mathrm{p}$-value $<0.05$ and sample size $(\mathrm{n}=36)$. $\mathrm{TiO}_{2}$ treatments $(0,100,200,500$, and $1000 \mathrm{mg} / \mathrm{kg}$ of dry soil) were treated as a fixed effect factor.

\begin{tabular}{llllll}
\hline Source & Df & Adj SS & Adj MS & F-Value & P-Value \\
\hline Treatment & 4 & 293.5 & 73.37 & 2.514 & 0.0758 \\
Residuals & 19 & 554.5 & 29.19 & & \\
\hline
\end{tabular}

ANOVA table for number of tassel heads of S. bicolor grown in soil to full maturity. The test used for ANOVA is general linear model with a significant level p-value $<0.05$ and sample size $(\mathrm{n}=36)$. $\mathrm{TiO}_{2}$ treatments $(0,100,200,500$, and $1000 \mathrm{mg} / \mathrm{kg}$ of dry soil) were treated as a fixed effect factor.

\begin{tabular}{llllll}
\hline Source & Df & Adj SS & Adj MS & F-Value & P-Value \\
\hline Treatment & 4 & 0.2 & 0.0500 & 0.114 & .976 \\
Residuals & 19 & 8.3 & 0.4368 & & \\
\hline
\end{tabular}

ANOVA table for number of tillers of S. bicolor grown in soil to full maturity. The test used for ANOVA is general linear model with a significant level $\mathrm{p}$-value $<0.05$ and sample size $(\mathrm{n}=36)$. $\mathrm{TiO}_{2}$ treatments $(0,100,200,500$, and $1000 \mathrm{mg} / \mathrm{kg}$ of dry soil) were treated as a fixed effect factor.

\begin{tabular}{llllll}
\hline Source & Df & Adj SS & Adj MS & F-Value & P-Value \\
\hline Treatment & 4 & 2.225 & 0.5562 & 0.518 & 0.723 \\
Residuals & 19 & 20.400 & 1.0737 & & \\
\hline
\end{tabular}


ANOVA table for damage level (\% of plant damaged) of $S$. bicolor grown in soil to full maturity. The test used for ANOVA is general linear model with a significant level p-value $<$ 0.05 and sample size $(\mathrm{n}=36)$. $\mathrm{TiO}_{2}$ treatments $(0,100,200,500$, and $1000 \mathrm{mg} / \mathrm{kg}$ of dry soil $)$ were treated as a fixed effect factor.

\begin{tabular}{llllll}
\hline Source & Df & Adj SS & Adj MS & F-Value & P-Value \\
\hline Treatment & 4 & 2384 & 596.1 & 2.174 & 0.111 \\
Residuals & 19 & 5208 & 274.1 & & \\
\hline
\end{tabular}

ANOVA table for dry weight of shoots of $S$. bicolor grown in soil to full maturity. The test used for ANOVA is general linear model with a significant level $\mathrm{p}$-value $<0.05$ and sample size $(\mathrm{n}=$ $36)$. $\mathrm{TiO}_{2}$ treatments $(0,100,200,500$, and $1000 \mathrm{mg} / \mathrm{kg}$ of dry soil) were treated as a fixed effect factor.

\begin{tabular}{llllll}
\hline Source & Df & Adj SS & Adj MS & F-Value & P-Value \\
\hline Treatment & 4 & 666.1 & 166.52 & 2.115 & 0.113 \\
Residuals & 19 & 1468.3 & & & \\
\hline
\end{tabular}

ANOVA table for dry weight of roots of S. bicolor grown in soil to full maturity. The test used for ANOVA is general linear model with a significant level $\mathrm{p}$-value $<0.05$ and sample size $(\mathrm{n}=$ $36)$. $\mathrm{TiO}_{2}$ treatments $(0,100,200,500$, and $1000 \mathrm{mg} / \mathrm{kg}$ of dry soil) were treated as a fixed effect factor.

\begin{tabular}{llllll}
\hline Source & Df & Adj SS & Adj MS & F-Value & P-Value \\
\hline Treatment & 4 & 82.56 & 20.64 & 1.915 & 0.149 \\
Residuals & 19 & 204.80 & 10.78 & & \\
\hline
\end{tabular}


ANOVA table for dry weight of tassel heads of $S$. bicolor grown in soil to full maturity. The test used for ANOVA is general linear model with a significant level p-value $<0.05$ and sample size $(\mathrm{n}=36) . \mathrm{TiO}_{2}$ treatments $(0,100,200,500$, and $1000 \mathrm{mg} / \mathrm{kg}$ of dry soil $)$ were treated as a fixed effect factor.

\begin{tabular}{lccccc}
\hline Source & Df & Adj SS & Adj MS & F-Value & P-Value \\
\hline Treatment & 4 & 176.7 & 44.19 & 1.012 & 0.427 \\
Residuals & 18 & 786.0 & 43.67 & & \\
\hline
\end{tabular}

ANOVA table for water content (dry weight/ fresh weight) of shoots of $S$. bicolor grown in soil to full maturity. The test used for ANOVA is general linear model with a significant level pvalue $<0.05$ and sample size $(\mathrm{n}=36)$. $\mathrm{TiO}_{2}$ treatments $(0,100,200,500$, and $1000 \mathrm{mg} / \mathrm{kg}$ of dry soil) were treated as a fixed effect factor.

\begin{tabular}{llllll}
\hline Source & Df & Adj SS & Adj MS & F-Value & P-Value \\
\hline Treatment & 4 & 2058 & 514.5 & 1.237 & 0.329 \\
Residuals & 19 & 7900 & 415.8 & & \\
\hline
\end{tabular}

ANOVA table for water content (dry weight/ fresh weight) of roots of S. bicolor grown in soil to full maturity. The test used for ANOVA is general linear model with a significant level p-value $<$ 0.05 and sample size $(\mathrm{n}=36) . \mathrm{TiO}_{2}$ treatments $(0,100,200,500$, and $1000 \mathrm{mg} / \mathrm{kg}$ of dry soil $)$ were treated as a fixed effect factor. $* *$ indicates significance level of $p<0.005$

\begin{tabular}{llllll}
\hline Source & Df & Adj SS & Adj MS & F-Value & P-Value \\
\hline Treatment & 4 & 9202 & 2300.5 & 5.561 & $0.00388^{* *}$ \\
Residuals & 19 & 7860 & 413.7 & & \\
\hline
\end{tabular}


ANOVA table for water content (dry weight/ fresh weight) of tassel heads of S. bicolor grown in soil to full maturity. The test used for ANOVA is general linear model with a significant level pvalue $<0.05$ and sample size $(\mathrm{n}=36)$. $\mathrm{TiO}_{2}$ treatments $(0,100,200,500$, and $1000 \mathrm{mg} / \mathrm{kg}$ of dry soil) were treated as a fixed effect factor.

\begin{tabular}{llllll}
\hline Source & Df & Adj SS & Adj MS & F-Value & P-Value \\
\hline Treatment & 4 & 4596 & 1148.9 & 1.219 & 0.337 \\
Residuals & 18 & 16965 & 942.5 & & \\
\hline
\end{tabular}

